\title{
Dynamical characteristics of the Cape Verde frontal zone*
}

\author{
P. PÉREZ-RODRÍGUEZ, J.L. PELEGRÍ and A. MARRERO-DÍAZ \\ Departamento de Física, Facultad de Ciencias del Mar, Universidad de Las Palmas de Gran Canaria, \\ 35017 Las Palmas de Gran Canaria, Canary Islands, Spain.
}

\begin{abstract}
SUMMARY: We analysed historical data (Fraga and Manríquez, 1974; Manríquez and Fraga, 1978) to investigate the relation between the position of the Cape Verde frontal region and the geostrophic velocity field in summer and winter. The position of the front is well determined in the plotting of the salinity and nutrient distributions in isopycnic coordinates. The geostrophic velocity shows sharp gradients as a function of density and distance on sections normal to the coast. These gradients are reasonable well correlated with the frontal position and indicate the existence of strong meridional interleaving. The flow field relative to $400 \mathrm{~m}$ illustrates this interleaving as fluctuations on a westward mean flow. The surface temperature distribution undergoes very large latitudinal displacements but may help to locate the presence of north and south surface water.
\end{abstract}

Key words: Cape Verde, frontal zone, water masses, geostrophic transport, isopycnic coordinates.

\section{INTRODUCTION}

The upper thermocline waters of the North Atlantic Subtropical Gyre (NASG) off West Africa flow south until latitudes near Cape Blanc, where they turn west, away from the coast. The southward flow is commonly identified with the Canary Current, while the westward turn is thought to be the beginning of the North Equatorial Current. The separation from the African coast and slope takes place rather abruptly, at the Cape Verde frontal system. It prevents southward advection of the NASG thermocline waters, leaving behind what has been called the shadow zone (Luyten et al. 1983; Sarmiento et al., 1982; Kawase and Sarmiento, 1985; Láiz et al., 2001). This dynamically very complex region sepa-

\footnotetext{
*Received February 28, 2000. Accepted August 21, 2000.
}

rates, and merges, two rather distinct water masses: North Atlantic Central Water (NACW) and South Atlantic Central Water (SACW) (Fraga, 1974; Hughes and Barton, 1974; Barton et al., 1977; Manríquez and Fraga, 1982; Barton and Hughes, 1982; Hagen, 1985; Zenk et al., 1991).

Fraga (1974) and Manríquez and Fraga (1982) (hereafter $\mathrm{F}$ and MF respectively) examined the water mass distributions in the Cape Verde frontal system off Cape Blanc between $16^{\circ} \mathrm{N}$ and $24^{\circ} \mathrm{N}$, using data collected in three different months. Their hydrographic data, which goes down to $1000 \mathrm{~m}$, illustrate the vertical and horizontal distribution of the NACW and SACW. Their results show rather sharp gradients in temperature and salinity in the upper 400 to $600 \mathrm{~m}$, reflecting the transition between these two water types, while the lower half of the water column (600 to $1000 \mathrm{~m}$ ) was occupied 
by NACW. In the upper $100 \mathrm{~m}$ they found an even larger contrast in temperature and salinity, with high-salinity and low-temperature northern waters separated from very low-salinity and high-temperature southern waters. The temperature of this surface water, however, varies seasonally, with temperatures 5 or $6^{\circ} \mathrm{C}$ higher in November than in March.

One important aspect of the Cape Verde frontal region is the compensating character of the temperature and salinity fields, which causes the horizontal density gradients to be relatively small across the front. This peculiarity is probably an important factor in reducing the vertical shear of the horizontal velocity in the frontal region (Rodríguez-Santana et al., 1999). As a result, the frontal region is likely to be rather stable in the vertical, with low diapycnal exchange of water properties, which in turn is responsible for the maintained gradients in other properties such as temperature, salinity and nutrients.

From the above point of view the Cape Verde frontal system is an effective barrier between different water masses (rather than a blender: for a nice discussion see Bower et al., 1985) and water exchange has to take place mainly as the result of large-scale horizontal instabilities. Such instabilities, expressed as major interleaving of water masses across the system, have been clearly reported in previous studies of this region and are responsible for the high temporal variability in the frontal position. Satellite images of sea surface temperature provide a vivid illustration of this variability but, away from the coastal upwelling region, these have to be seen with caution because of the masking by the surface mixed layer. In any case, the surface temperature field patterns associated with the giant Cape Blanc filament expelled towards the interior ocean (Gabric et al., 1993), precisely as a result of the convergence of NACW and SACW at the frontal region, is a clear indicator of the variability.

Several authors have studied the distribution and variability of water masses in the Cape Verde front during different seasons (F and MF; Hughes and Barton, 1974; Barton and Hughes, 1982; Fraga et al., 1985). All prior dynamic studies, however, have either dealt with a single hydrographic cruise (Zenk et al., 1991) or have used rather limited spatial resolution (Barton, 1987). In this work we will analyse the wonderful data sets used by $\mathrm{F}$ and MF, in an attempt to investigate the relation between the frontal structure and the flow patterns at the end of the winter and summer seasons. Additionally, since water exchange has to take place principally along isopycnals, we will examine the distribution of salinity and nutrients using isopycnic coordinates. The frontal position will be where these properties show maximum epipycnic gradients. Finally, we will use infrared images of the water surface (Van Camp and Jewell, 1990) to help us locate the interleaving of south surface and north surface waters (SS and NS respectively) in both seasons.

\section{DATA REPRESENTATION ON ISOPYCNIC COORDINATES}

Fraga and Manríquez (1974) and Manríquez and Fraga (1978) originally published the data used in this work. The hydrographic data correspond to cruises Atlor 2 (March 1973) and Atlor 7 (November 1975), and hence may be considered as representative of the conditions at the end of winter and summer respectively. The location of the stations was almost the same for both cruises and is presented in Figure 1. The data cover a region about $200 \mathrm{~km}$ wide along some $500 \mathrm{~km}$ of coastline, but there are two hydrographic sections normal to the coast of nearly $450 \mathrm{~km}$ length. These sections, indicated as

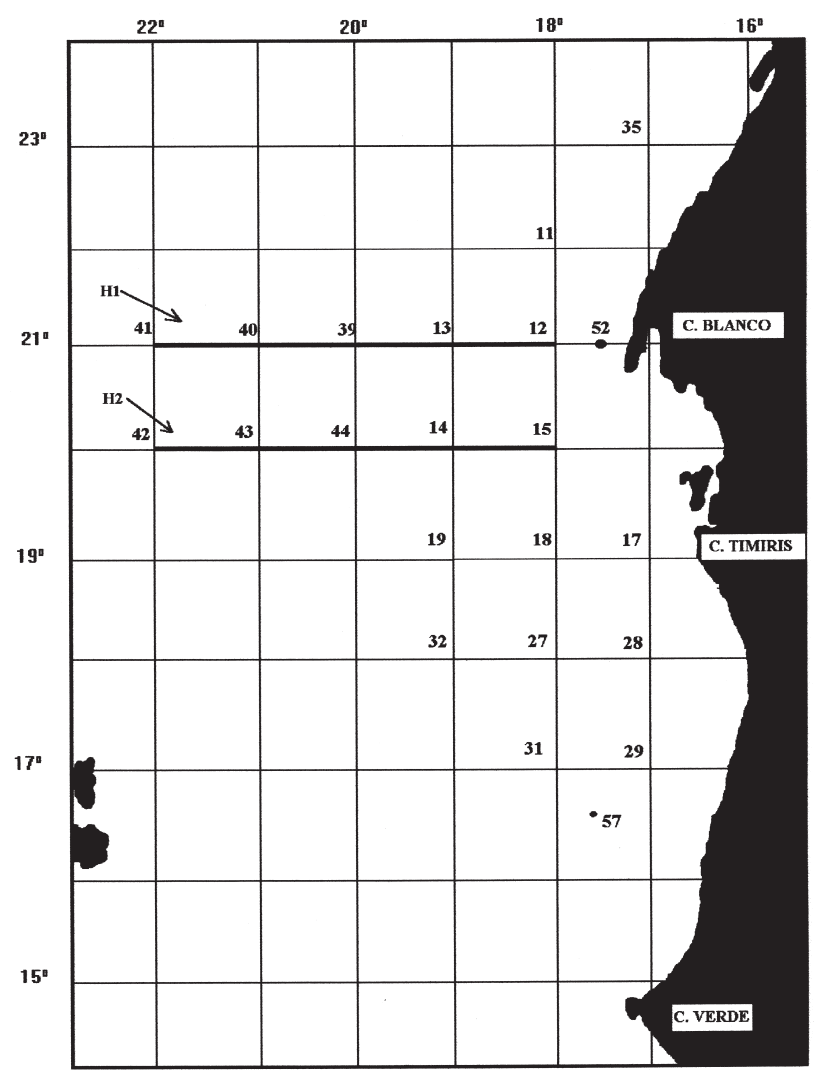

FIG. 1. - Location of hydrographic stations during Atlor 2 (March 1973) and Atlor 7 (November 1975). 

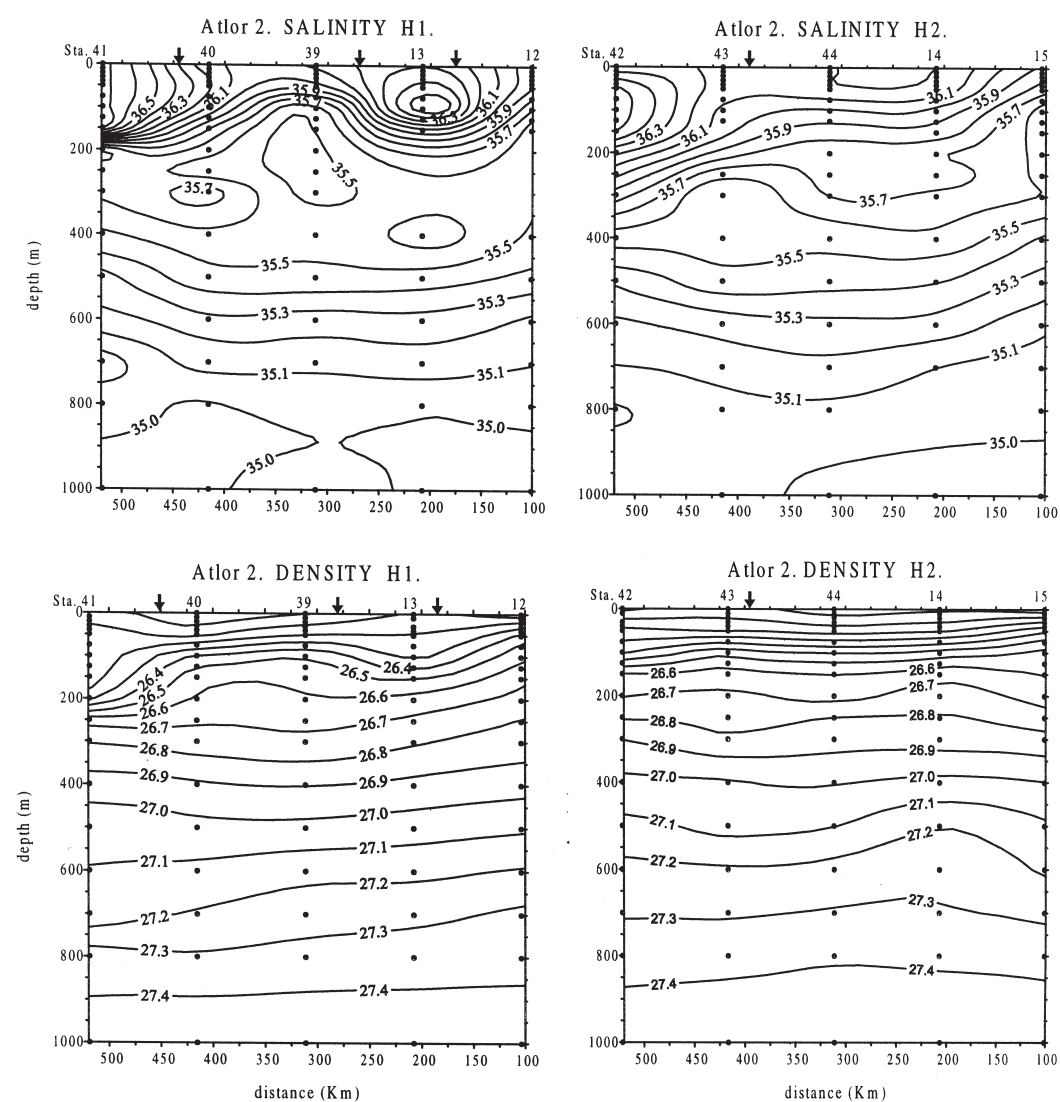

FIG. 2. - Salinity and density distributions, as a function of depth, along H1 and H2 during Atlor 2 (March 1973). The arrows on top show the position of the front as where the $36.0 \%$ isohaline intersects the $150 \mathrm{~m}$ depth.
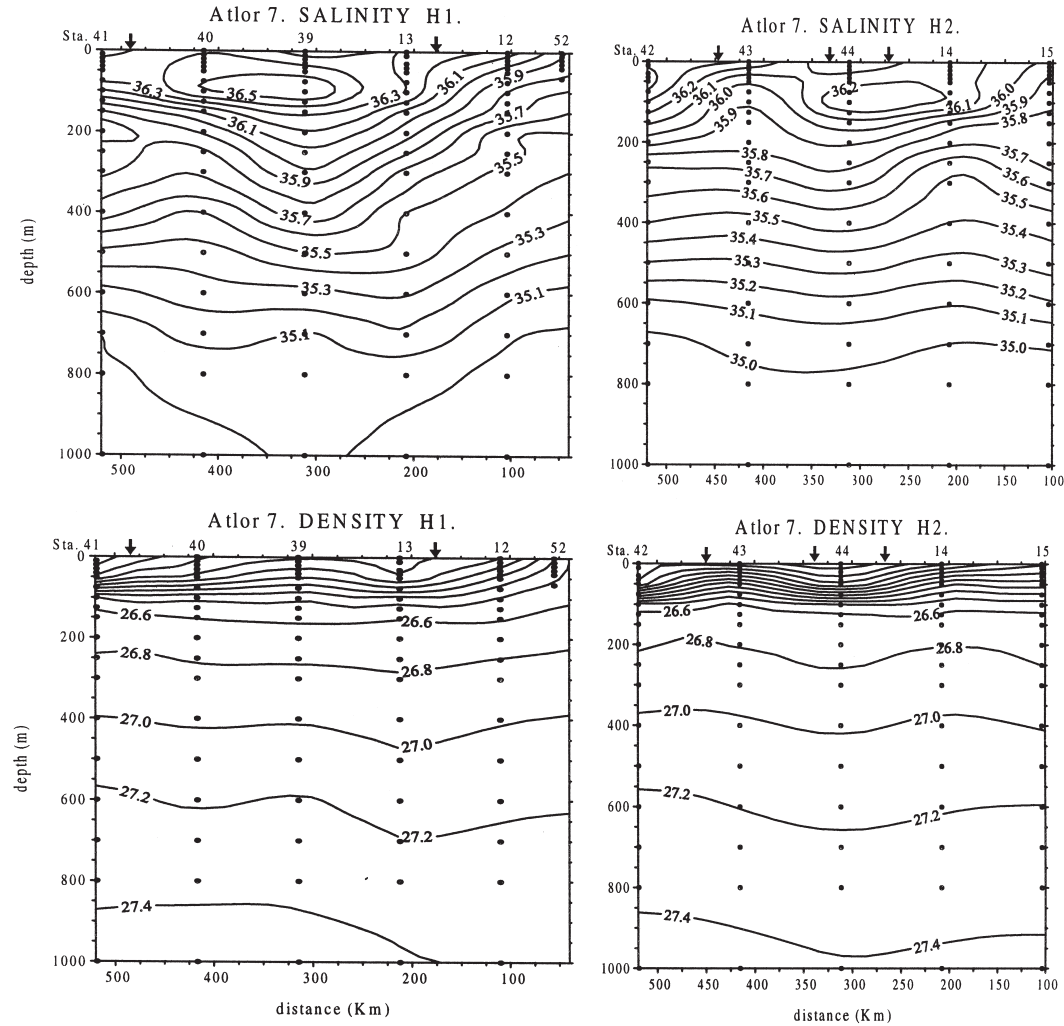

FIG. 3. - Salinity and density distributions, as a function of depth, along H1 and H2 during Atlor 7 (November 1975). The arrows on top show the position of the front as where the $36.0 \%$ isohaline intersects the $150 \mathrm{~m}$ depth. 
$\mathrm{H} 1$ and $\mathrm{H} 2$ in Figure 1, are of key importance to examine the water structure and flow of the boundary region.

\section{Distributions on sections normal to the coast}

The arrows on top of Figures 2 and 3 show the position of the front, defined as where the $36.0 \%$ o isohaline intersects the $150 \mathrm{~m}$ depth (Barton, 1987; Zenk et al., 1991). In the 0-400 m layer the regions of relatively salty (fresh) water correspond to NACW (SACW); in the top $100 \mathrm{~m}$ salinity values close to $36.5 \%$ \% (35.4\%o) are indicative of NS (SS).

Figure 2 illustrates the conditions during Atlor 2 (March 1973; see also Fig. 4 in F). In the top 400 m there is SACW in the central and easternmost portions of $\mathrm{H} 1$ and in all but the westernmost portion of $\mathrm{H} 2$; the very salty surface water at the western end of H1 is indicative of NS. The compensating character of temperature and salinity is clear in this figure, where the isopycnals appear rather flat, except in the western surface layer of $\mathrm{H} 1$ due to the presence of NS. From Figure 2 alone it is not possible to differentiate between NACW and NS near the surface at Station 13 (Section H1), and the homogeneous salinity layer between 200 and 450 m disguises the usual character of the frontal region.

Figure 3 shows the conditions during Atlor 7 (November 1975; see also Fig. 29 in MF). In the top $200 \mathrm{~m}$ there is SACW in the eastern portion of $\mathrm{H} 1$ and in the mid-western and eastern portions of $\mathrm{H} 2$; the very salty surface water in most of $\mathrm{H} 1$ is indicative of NS. Again, the density is compensated over most of the sections and the maximum gradients are at the surface due to the contrast between NS and SS.

A comparison of the $36.0 \%$ - $150 \mathrm{~m}$ intersection criterion with the percentages of NACW and SACW (as obtained by $\mathrm{F}$ and MF) suggests that the presence of NS and SS may indeed misrepresent the existence of a boundary or front. A different alternative is to plot the salinity and nutrient distributions in Sections $\mathrm{H} 1$ and $\mathrm{H} 2$ against density, as in Figures 4 and 5. Any strong salinity/nitrate gradient at constant density is indicative of a frontal region where epipycnal exchange is inhibited. When looking at each of these distributions we must keep in mind that their upper portion, for sigma-t less than 26.5, roughly corresponds to the top $150 \mathrm{~m}$, where NS and SS are usually found. Hence, the actual boundary between NACW and SACW will correspond to those places with strong epipycnal gradients for densities of 26.5 sigma-t or larger. Taking this into account, we may appreciate that the position of the front according to the $36.0 \%-150 \mathrm{~m}$ intersection criterion may not always be correct. This is particularly true for the Atlor 7 (November) sections: according to the criterion of maximum epipycnal gradients the front crosses $\mathrm{H} 1$ at about 220 and 350 $\mathrm{km}$ and $\mathrm{H} 2$ at about $180 \mathrm{~km}, 360 \mathrm{~km}$ and $480 \mathrm{~km}$.

\section{Distributions on isopycnic surfaces}

Figures 6 and 7 show the salinity and nitrate distributions over three different isopycnals (sigma-t equal to 26.5, 26.8 and 27.1) during Atlor 2 and Atlor 7 respectively. The 26.5 sigma-t surface corresponds to near surface water and it should illustrate changes between NACW, SACW and the warm surface waters. The 26.8 sigma-t surface is located deep enough that no surface water is found here, so any strong gradient on this surface should be indicative of a boundary between NACW and SACW. The 27.1 sigma-t surface is located at depths of more than $500 \mathrm{~m}$, where $\mathrm{F}$ and MF found little gradients in water-mass composition.

Figure 6, corresponding to the Atlor 2 cruise, illustrates the existence of strong interleaving between NACW and SACW in the northern region at all three surfaces, and a predominance of SACW in the southeastern region (see Figs. 5 to 8 in F). Figure 7, which corresponds to the Atlor 7 cruise, shows a predominance of NACW, with SACW found only in a band near the African slope (see Figs. 25 to 29 in MF). In particular, the NACW signal is very intense around Station 39 at all three surfaces and around Station 18 at the upper surface.

\section{VELOCITY FIELDS}

In this section we will examine the north-south geostrophic velocity field, as calculated referred either to $1000 \mathrm{~m}$ or to the bottom floor (whichever is shallower). The meridional orientation of the coast will allow us to integrate the velocity transport from the coast and to plot the streamlines of water transport in the top 400 and $800 \mathrm{~m}$.

\section{Geostrophic velocity field}

Figure 8 illustrates the meridional velocity field relative to $1000 \mathrm{~m}$ for both Atlor 2 and Atlor 7 across $\mathrm{H} 1$ and $\mathrm{H} 2$, but plotted against density rather than depth; northward velocities are taken as posi- 

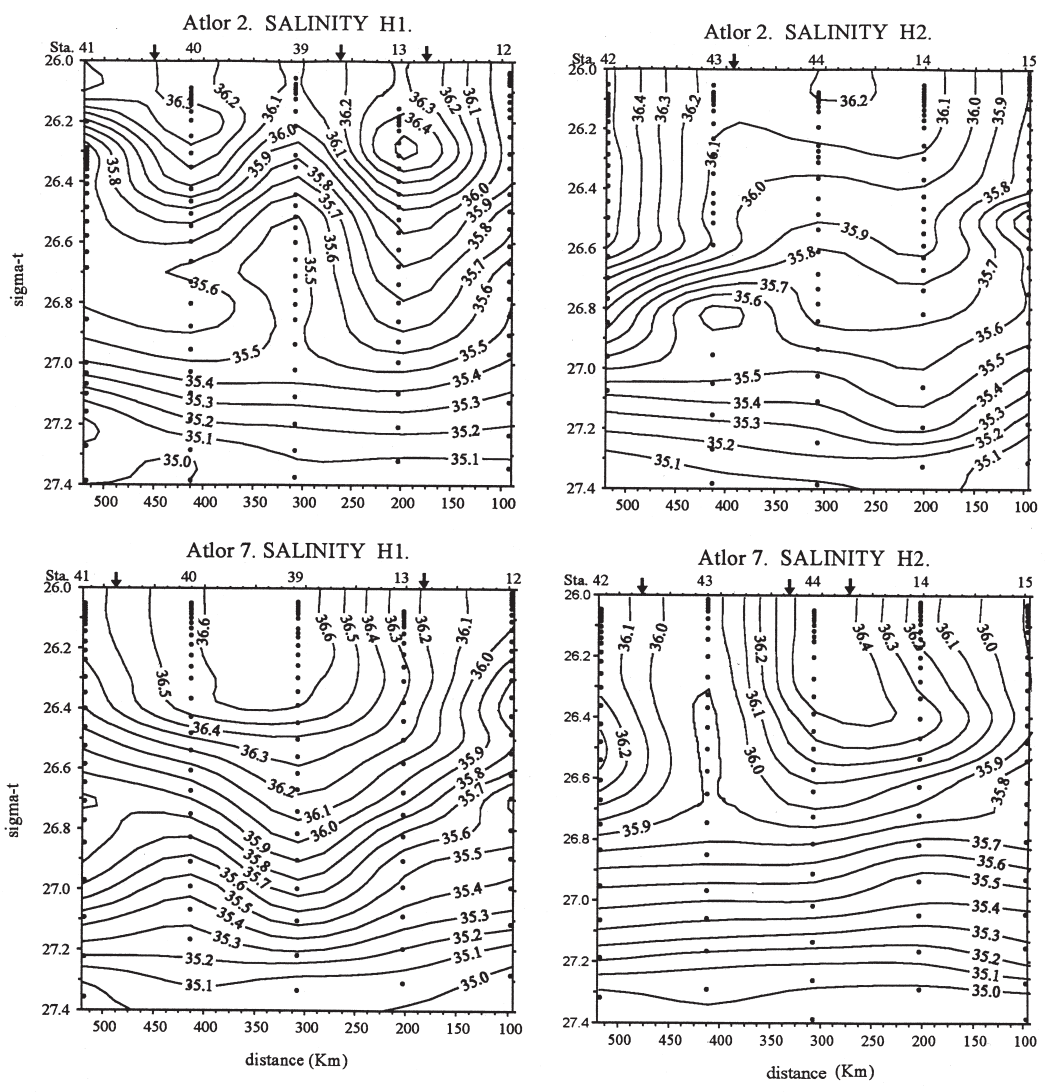

FIG. 4. - Salinity distributions, as a function of density, along H1 and H2, during Atlor 2 and Atlor 7.
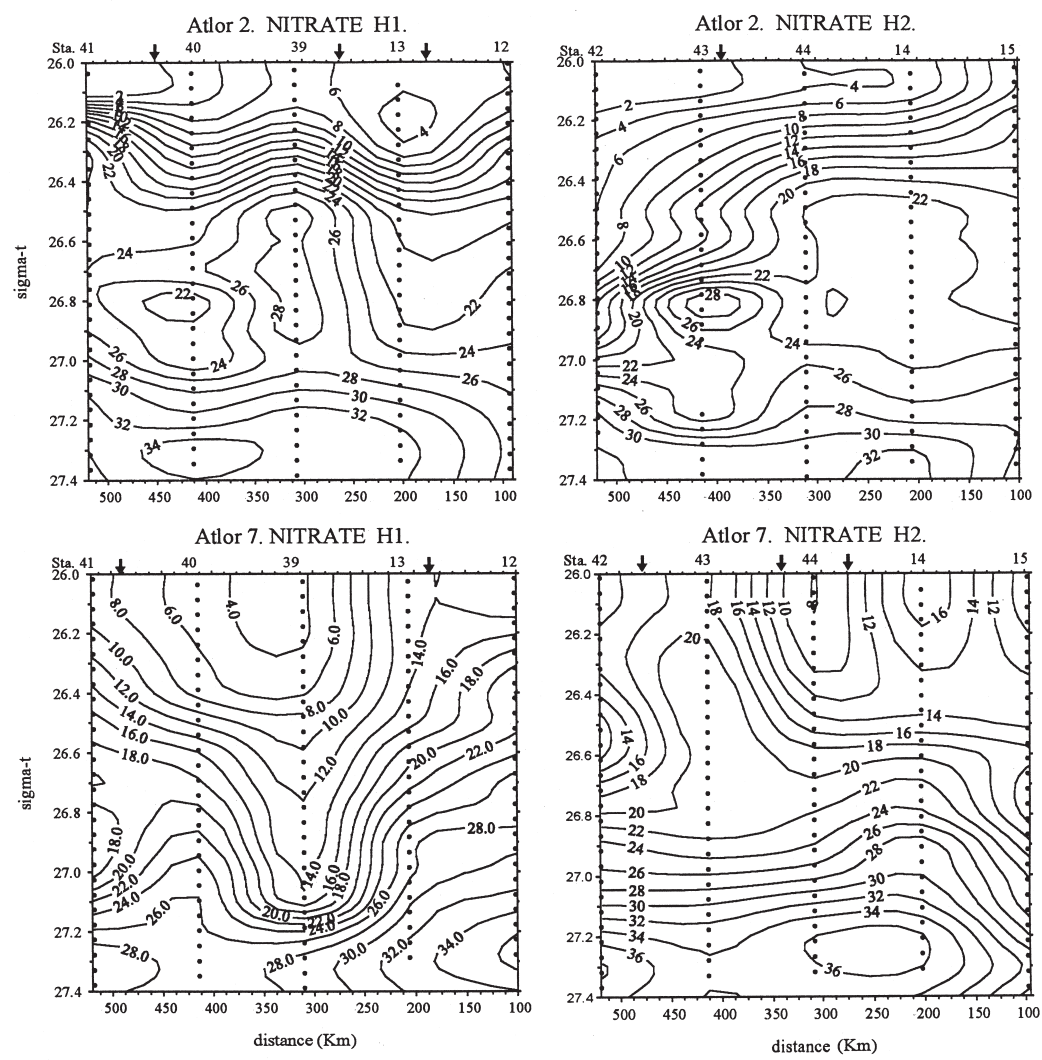

FIG. 5. - Nitrate distributions, as a function of density, along $\mathrm{H} 1$ and $\mathrm{H} 2$, during Atlor 2 and Atlor 7. 

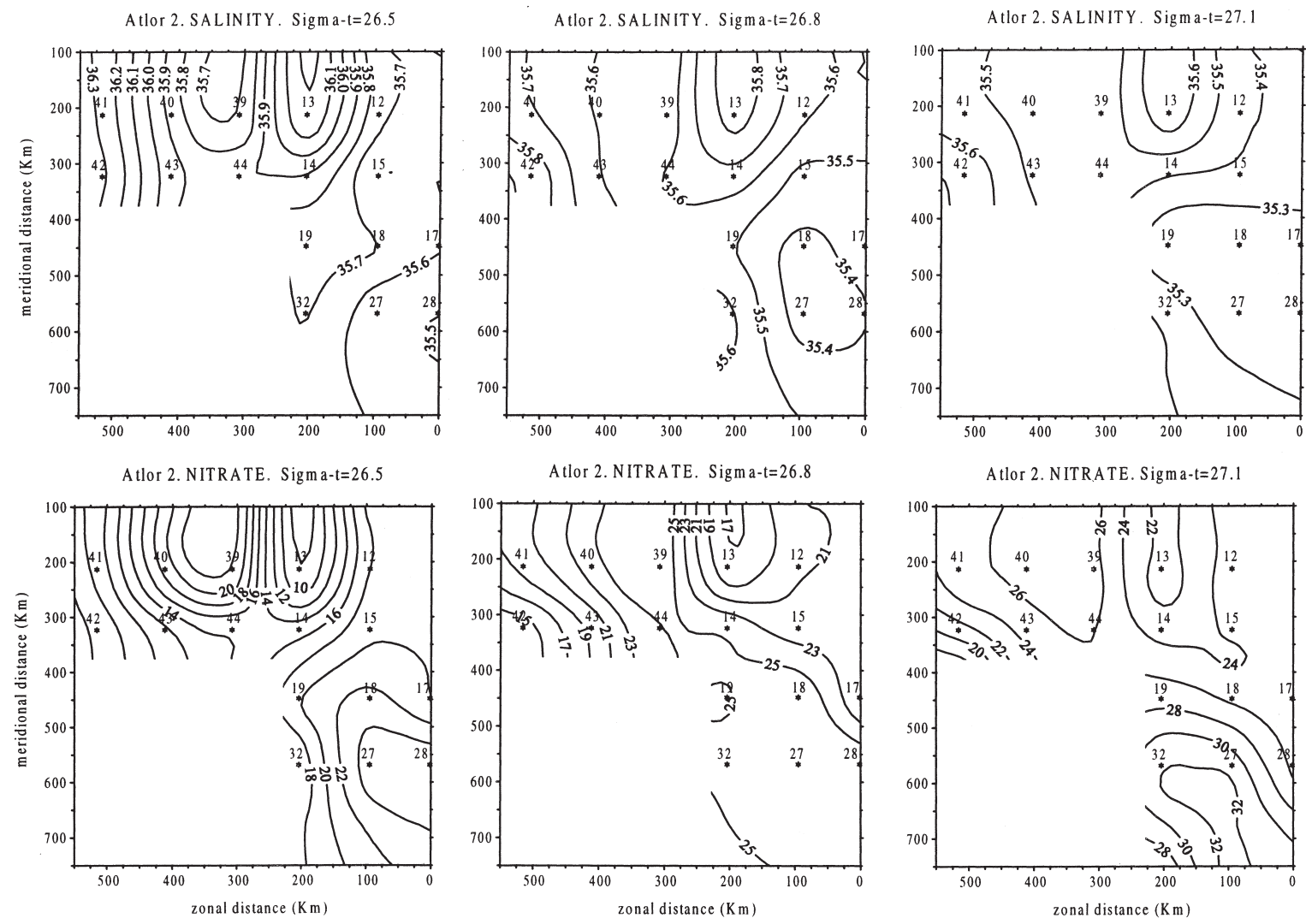

FIG. 6. - Salinity and nitrate distributions over three different isopycnals during Atlor 2.
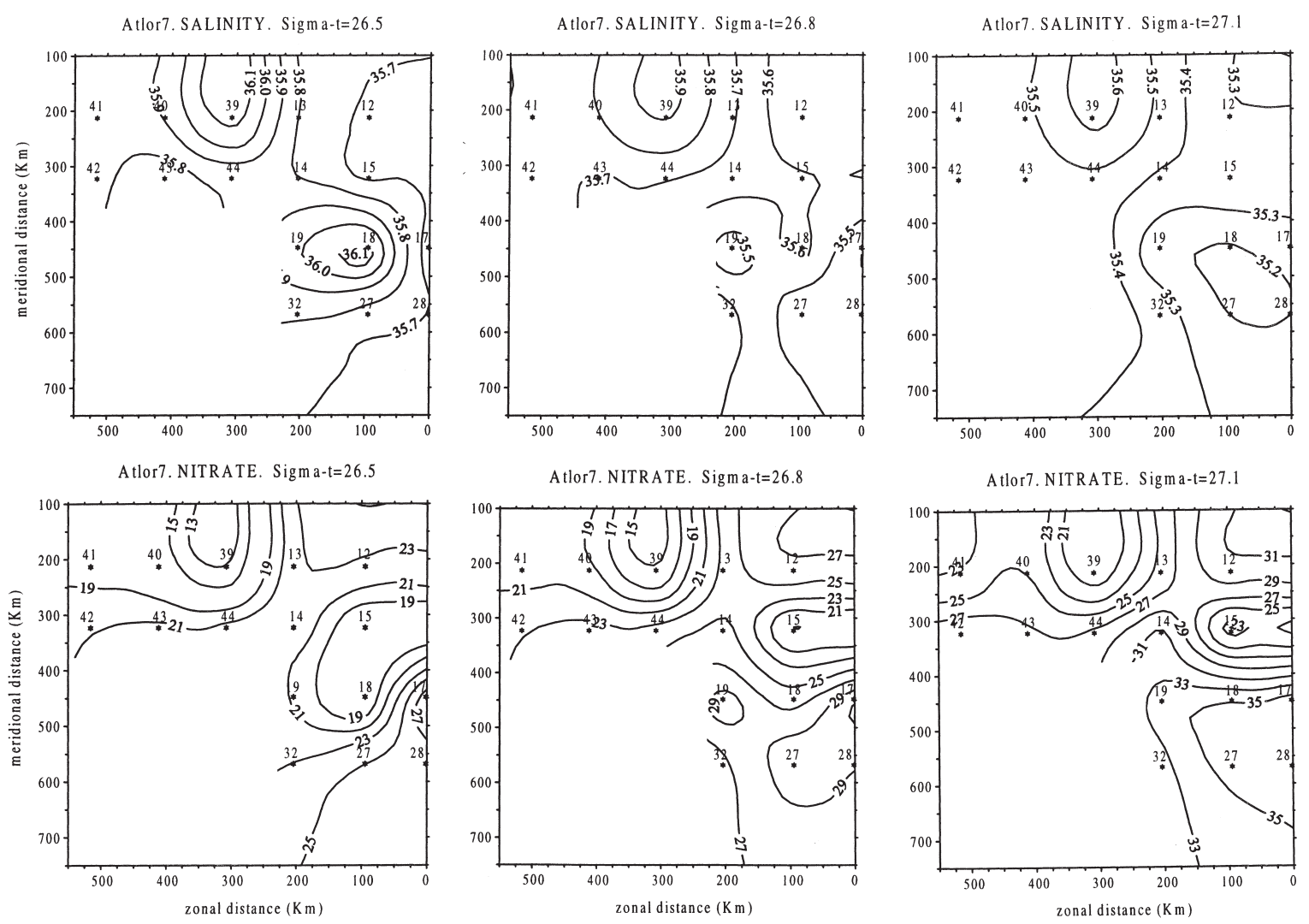

FIG. 7. - Salinity and nitrate distributions over three different isopycnals during Atlor 7. 
Atlor 2. VELOCITY H1.

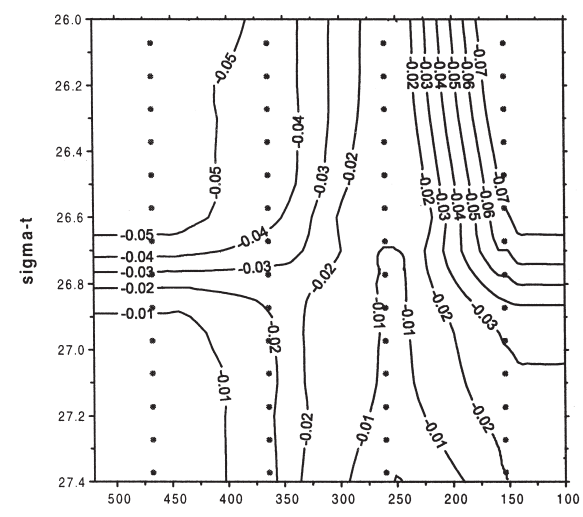

Atlor 7. VELOCITY H2.

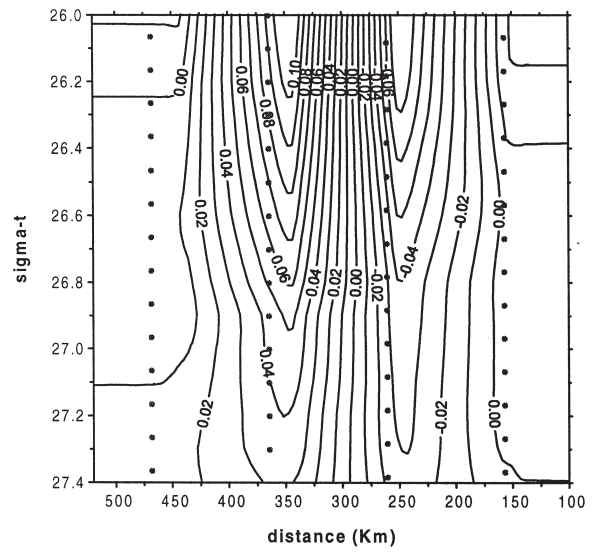

Atlor 2. VELOCITY H2.

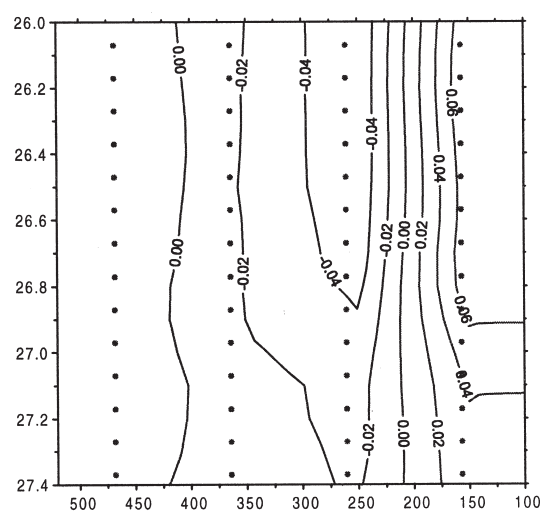

Atlor 7. VELOCITY H2.

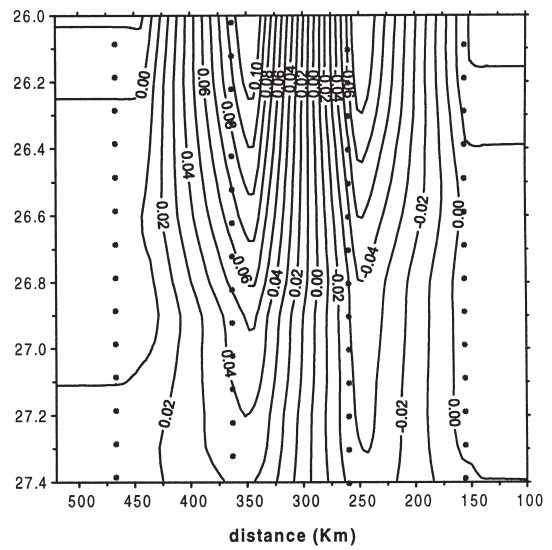

FIG. 8. - Geostrophic velocities normal to $\mathrm{H} 1$ and $\mathrm{H} 2$, interpolated as a function of density, during Atlor 2 and Atlor 7 . Reference level is 1000 m.

tive. During Atlor 2 the velocities across both sections are dominantly negative, but there is northward flow across $\mathrm{H} 2$ at both the eastern and western ends. The speed is maximum negative across H1, precisely where NACW is found, and it is positive across $\mathrm{H} 2$ near the coast, where SACW is found. During Atlor 7 the north-south velocity alternates across both sections, maintaining little correspondence to the water-mass distribution, which suggests that it is undergoing rapid deformation.

\section{Depth integrated streamlines}

Figure 9 presents the water transport integrated down to 400 and $800 \mathrm{~m}$ for both cruises. These depths were chosen based on the water mass distribution found by $\mathrm{F}$ and MF, where NACW was always predominant below $400 \mathrm{~m}$. The integration assumes zero flow at the location of the easternmost station and moves zonally towards the interior ocean (a right-hand coordinate system is maintained, with the $x$ axis pointing into the African continent and the $y$ axis pointing north).
A striking feature of the water flow referred to $400 \mathrm{~m}$ is the strong meridional convergence that forces the flux to turn westward between $\mathrm{H} 1$ and $\mathrm{H} 2$. This convergence is still quite clear for the water flow referred to $800 \mathrm{~m}$ during Atlor 2 but not so during Atlor 7, in which case the water flows north over most of the domain. The intense water interleaving found by $\mathrm{F}$ and $\mathrm{MF}$, and also reported by Barton and Hughes (1982) and Barton (1987), has the form of pronounced north-south meanders immersed in the westward flow.

\section{Surface mixed layer}

A result that may be inferred from the distribution of south surface and north surface waters, as presented by $\mathrm{F}$ and $\mathrm{MF}$, is that surface interleaving is less pronounced by the end of the summer season, with SS well located south of the frontal region. The intensity of surface water interleaving may also be determined from the monthly maximum sea surface temperature distribution, as obtained from infrared satellite observations between 1982 and 1985 (Van 


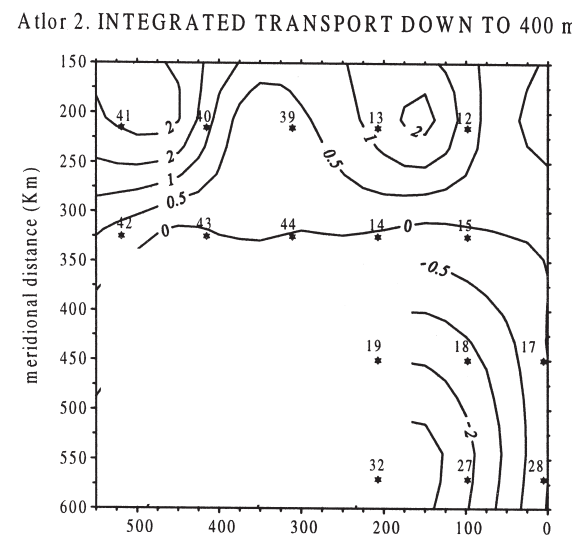

Atlor 2. INTEGRATED TRANSPORT DOWN TO $800 \mathrm{~m}(\mathrm{~Sv})$

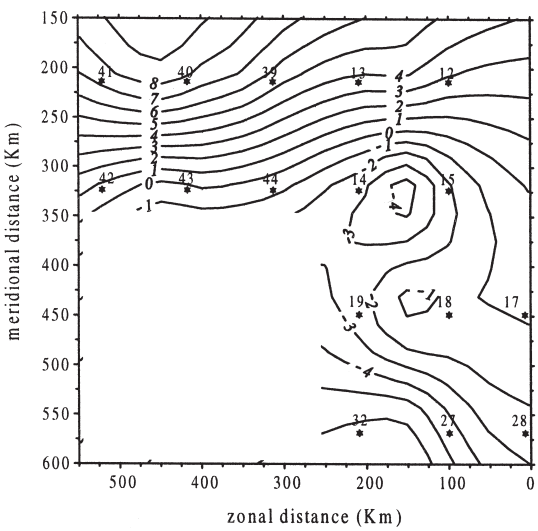

Atlor 7. INTEGRATED TRANSPORT DOWN TO $400 \mathrm{~m}$ (Sv)

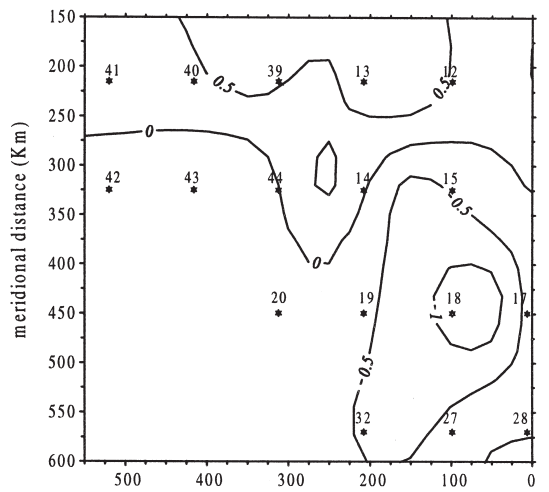

Atlor 7. INTEGRATED TRANSPORT DOWN TO $800 \mathrm{~m}(\mathrm{~Sv})$

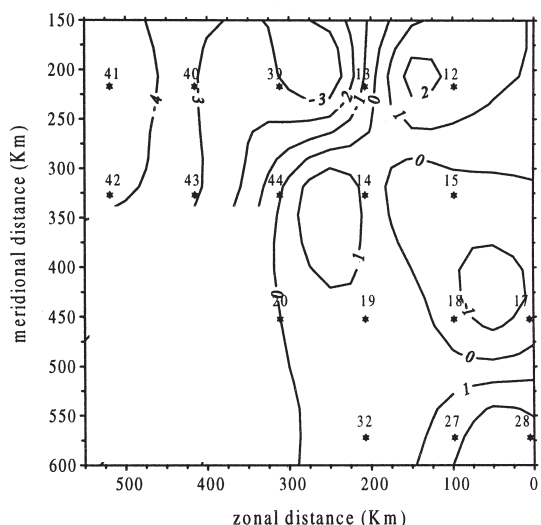

FIG. 9. - Water transport integrated down to 400 and $800 \mathrm{~m}$, for both cruises. Transport is taken as zero in the station nearest to the coast.

Camp and Jewell, 1990). These maps allow us to obtain the position of the $21.5^{\circ} \mathrm{C}$ and $25^{\circ} \mathrm{C}$ surface isothermals in March and November (Fig. 10). This figure shows very large latitudinal movements of the isothermals, mainly due to water heating and cooling during the summer and winter seasons. The positions of the $21.5^{\circ} \mathrm{C}$ isotherm in March and the $25^{\circ} \mathrm{C}$ isotherm in November are of particular relevance because these isotherms represent the typical values of SS and NS as shown in F and MF. Close to the African coast the isotherms show larger interleaving in March than in November.

\section{CONCLUSIONS}

Isopycnic coordinates may be of valuable help in identifying frontal boundaries in regions where the temperature and salinity fields are compensating, such as in the Cape Verde frontal region. Here we have shown that the $36.0 \%$ - $150 \mathrm{~m}$ intersection criterion may not always be the best choice to locate the Cape Verde front. Instead, we have illustrated that the representation of the salinity and nutrient fields in isopycnic coordinates shows the presence of actual fronts as the place where the exchange of properties along isopycnals is inhibited.

The distribution of salinity, nutrients and meridional velocity in the region is very complex, illustrating strong interleaving between different water masses. Some correspondence between NACW (SACW) and southward (northward) flow may be found, although this association is often unclear, which suggests that the water flow is continuously deforming the density field. During Atlor 7, for example, the dominant flow was north although the prevalent water mass was NACW, possibly indicating that the whole frontal zone had been displaced south beyond its mean position and had to shift north. In general we may conclude that the water flow shows strong convergence between NACW and SACW, which causes the flux to turn westward. This zonal flow is characterised by the presence of unstable meanders, which are probably the origin of the observed interleaving.

The surface temperature field shows very large meridional excursions as the result of warming and cooling during the summer and winter seasons 

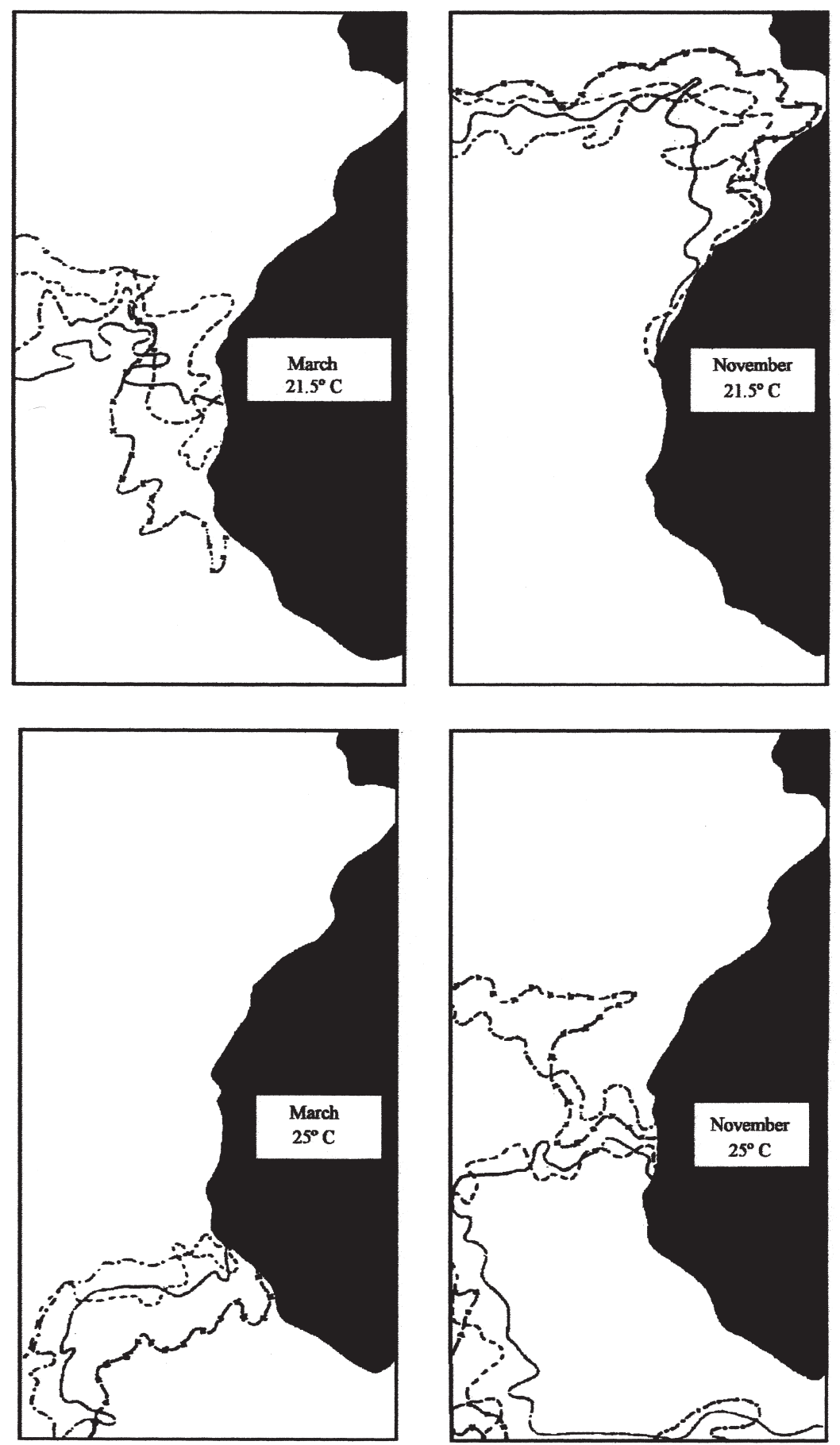

FIG. 10. - Surface position of the $21.5^{\circ} \mathrm{C}$ and $25^{\circ} \mathrm{C}$ isotherms in March and November, between 1982 and 1985 , as derived from infrared satellite observations.

respectively. These movements are clearly not associated with water advection. Nevertheless, near the coast, where the surface mixed layer is almost absent, the variability of surface water temperature as observed from satellite images may be indicative of spatial variability in the region. Both the hydrographic measurements and the satellitederived surface water temperature suggest that the zonal gradients are less intense in November than in March.

\section{ACKNOWLEDGEMENTS}

This work was supported by the Spanish government through CICYT's project MAR96-1893. The 
principal author, PPR, wishes to thank the Ministerio de Educación y Cultura of the Spanish government for funding during this work. The authors wish to thank Angel Rodríguez-Santana and three reviewers for a number of useful comments.

\section{REFERENCES}

Barton, E.D. - 1987. Meanders, eddies and intrusions in the thermocline front off northwest Africa. Oceanol. Acta, 10: 267-283.

Barton, E. D. and P. Hughes. - 1982. Variability of water mass interleaving off NW Africa. J. Mar. Res., 40: 963-984.

Bower, S. A., H.T. Rossby and J.L. Lillibridge. - 1985, The Gulf Stream: Barrier or blender? J. Phys. Oceanogr., 15, 24-32.

Fraga, F. - 1974. Distribution des masses d'eau dans l'upwelling de Mauritanie. Thetys, 6: 5-10.

Fraga, F., E.D. Barton and O. Llinás. - 1985. The concentration of nutrient salts in "pure" North and South Atlantic Central Waters. In. Symp. Upw. W. Afr., Inst. Inv. Pesq., Barcelona 1985, 1: 25-36.

Fraga, F. and M. Manríquez. - 1974. Hidrografía de la región de afloramiento del noroeste de Africa. Datos básicos de la campaña Atlor II del Cornide de Saavedra. Res. Exp. Cient. B/O Cornide., 3: 67-87.

Gabric, A.J., L. García, L. van Camp, L. Nykjaer, W. Eifler and W. Schrimpf. - 1993. Offshore export of shelf production in the Cape Blanc (Mauritania) giant filament as derived from coastal zone color scanner imagery. J. Geophys. Res. 98: 4697-4712.

Hernández-Guerra, A. and L. Nykjaer. - 1997. Sea Surface Variability off North-West Africa: 1981-1989. Int. J. Remote Sens., 18: 2539-2558.

Hagen, E. - 1985. A meandering intermediate front North-West off Cape Verde islands. Oceanogr. Trop., 20: 71-83.
Hughes, P. and E.D. Barton. - 1974. Stratification and water mass structure in the upwelling area off northwest Africa in April/May 1969. Deep-Sea Res., 21: 611-628.

Kawase, M. and J.L. Sarmiento. - 1985. Nutrients in the Atlantic thermocline. J. Geophys. Res. 90: 8961-8979.

Laiz, I., P. Sangrà, J.L. Pelegrí and A. Marrero-Díaz. - 2001. Sensitivity of an idealized subtropical gyre to the eastern boundary conditions. Sci. Mar., 65(Suppl. 1): 187-194.

Luyten, J., J. Pedlosky and H. Stommel. - 1983. The ventilated thermocline. J. Phys. Oceanogr. 13: 292-309.

Manríquez, M. and F. Fraga. - 1978. Hidrografía de la región de afloramiento del noroeste de Africa. Campaña Atlor VII. Res. Exp. Cient. B/O Cornide, 7: 1-32.

Manríquez, M. and F. Fraga. - 1982. The distribution of water masses in the upwelling region off Northwest Africa in November. Rapp. P. V Reun. Cons. Int. Explor. Mer, 39-47.

Rodríguez-Santana, A., J.L. Pelegrí, P. Sangrà and A. MarreroDíaz. - 1999. Diapycnal mixing in Gulf Stream meanders. $J$. Geophys. Res., 104: 25891-25912.

Sarmiento, J.L., C.G. Rooth and W. Roether. - 1982. The North Atlantic tritium distribution in 1972. J. Geophys. Res., 87: 8047-8056.

Schmitz, W.J. and M.S. McCartney. - 1993. On the north Atlantic circulation. Rev. Geophys. 31: 29-49.

Siedler, G. and R. Onken. - 1996. Eastern recirculation. In: W. Krauss (ed.), The Warmwatersphere of the North Atlantic Ocean, pp. 339-364. Gebruder Brontraeger, Berlin.

Stramma, L. - 1984. Geostrophic Transport in the Warm Water Sphere of the Eastern Subtropical North Atlantic. J. Mar. Res. 42: 537-558.

Stramma, L. and G. Siedler. - 1988. Seasonal Changes in the North Atlantic Subtropical Gyre. J. Geophys. Res. 93: 8111-8118.

Van Camp, L. and N. Jewell. - 1990. Time series of monthly maximum sea surface temperature for the central east Atlantic Ocean as derived from infrared satellite observations. Joint Research Center.

Zenk, W., B. Klein and M. Schroder. - 1991. Cape Verde Frontal Zone. Deep-Sea Res., 38, S1: s505-s530. 